\title{
miR-19a promotes vascular smooth muscle cell proliferation, migration and invasion through regulation of Ras homolog family member B
}

\author{
GENGXIN SUN ${ }^{1}$, HUI SONG ${ }^{2}$ and SUYA WU ${ }^{3}$ \\ ${ }^{1}$ Department of Cardiology, The Second Affiliated Hospital of Xi'an Medical University, Center for Clinical Medical Research of \\ Cardiovascular Diseases in Shaanxi Province, Xi'an, Shaanxi 710038; ${ }^{2}$ Electrocardiographic Room, Ankang Central Hospital, \\ Ankang, Shaanxi 725000; ${ }^{3}$ Department of Cardiology, Xingyuan Hospital, Yulin, Shaanxi 719000, P.R. China
}

Received January 18, 2019; Accepted July 10, 2019

DOI: 10.3892/ijmm.2019.4357

\begin{abstract}
Diabetic patients with high glucose exhibit vascular smooth muscle cell (VSMC) alteration. Thrombotic disease is related to erosion of an unstable plaque, the instability of which leads to ruptures, for example, a thin fibrous cap derived from VSMCs. VSMC proliferation, migration and invasion are related to thrombotic diseases, including atherosclerosis. MicroRNA-19a (miR-19a) has been reported to have pleiotropic functions in cancer cell survival, apoptosis and migration. The present study aimed to investigate the effect of miR-19a on VSMC proliferation, migration and invasion, and its mechanism. Cell Counting Kit- 8 and a propidium iodide kit were used to determine the proliferation and cycle of VSMCs. A cell migration assay was performed by scratching and Matrigel was used in a cell invasion assay. miR-19a binding to Ras homolog family member B (RHOB), and their protein and mRNA expressions were determined by performing a dual luciferase assay, western blotting and reverse transcription-quantitative PCR, respectively. It was demonstrated that miR-19a promoted the proliferation, migration and invasion of VSMCs, promoted the expressions of dual specificity phosphatase Cdc25A (CDC25A), cyclinD1, matrix metalloproteinase (MMP)-2, MMP-9, $\alpha$-smooth muscle actin ( $\alpha$-SMA) and
\end{abstract}

Correspondence to: Dr Suya Wu, Department of Cardiology, Xingyuan Hospital, 33 West Renmin Road, Yuyang, Yulin, Shaanxi 719000, P.R. China

E-mail: suyaw_wusy@163.com

Abbreviations: VSMCs, vascular smooth muscle cells; RHOB, Ras homolog family member B; CCK-8, Cell Counting Kit-8; miRNA/miR, microRNA; miR-19, microRNA-19a; PI, propidium iodide; RT-qPCR, reverse transcription-quantitative PCR; MMP, matrix metalloproteinase; $\alpha$-SMA, $\alpha$-smooth muscle actin; SM22 $\alpha$, smooth muscle $22 \alpha$; SOCS3, suppressor of cytokine signaling 3; TIA1, T-cell intracellular antigen-1

Key words: miR-19a, RHOB, VSMCs, migration, invasion smooth muscle $22 \alpha$ (SM22 $\alpha$ ), and inhibited suppressor of cytokine signaling 3 and RHOB expressions in VSMCs, while miR-19a had no effect on the expression of T-cell intracellular antigen-1. The miR-19a site bound to the RHOB gene position and inhibited RHOB to promote VSMC proliferation, invasion and migration, and increased MMP-2, MMP- $9, \alpha$-SMA and SM22 $\alpha$ expressions. The present study suggested that miR-19a could promote VSMC proliferation, migration and invasion via the cyclinD1/CDC25A and MMP/ $\alpha$-SMA/SM22 $\alpha$ signaling pathways. Moreover, miR-19a promoted proliferation, migration and invasion via the MMP/ $\alpha$-SMA/SM $22 \alpha$ signaling pathway by inhibiting RHOB, suggesting that miR-19a is a possible regulatory factor of RHOB.

\section{Introduction}

Patients with type 2 diabetes mellitus have a high risk of developing atherosclerosis (1), and a higher likelihood of restenosis after percutaneous coronary intervention (2). However, injecting insulin into a patient with diabetes does not affect restenosis (3). High glucose causes vascular smooth muscle cell (VSMC) alteration (4-6), which contributes to diabetic macrovasculopathy.

Atherosclerosis is a chronic disease and could lead to sudden death (7). As clinical consequences of atherosclerosis, myocardial infarction or stroke is not a consequence of gradual narrowing in the lumen but the thrombotic disease is related to acute rupture or erosion of an unstable plaque (8). A previous clinical imaging study identified that plaque instability led to ruptures, such as a thin fibrous cap-formed by extracellular matrix molecules from VSMCs, releasing lipids that accumulated extracellularly to form the necrotic core of the plaque (9). In addition, VSMCs in advanced lesions are generally regarded as having athero-protective properties, and a previous study demonstrated that VSMC proliferation even helped relieve atherogenesis (10). However, a previous study demonstrated that formation of atherosclerotic plaques can be inhibited by suppressing VSMC migration and proliferation (11). Hence, VSMC proliferation, migration and invasion are related to atherosclerosis; however, the specific mechanism of action still requires further elucidation. 
MicroRNA (miRNA/miR), which consist of 17-25 nucleotides, can lead to target mRNA degradation or translational suppression by interacting with the 3 ' untranslated region (3'UTR) of its target gene (12). Hence, miRNAs have been characterized throughout the creature genome (http://www. mirbase.org/), with potentially more to be found. Each miRNA could repress the translation of hundreds of mRNA $(13,14)$, producing complex changes in the protein expression field. A previous study has shown that miRNA expression took part in regulation networks in cell processes, including cell proliferation, apoptosis, invasion and migration (15), and miRNA levels were also correlated with patient survial and prognosis in cancer $(16,17)$. miRNAs have been increasingly reported to be involved in dysfunction of VSMCs, including VSMC calcification, proliferation and migration (18-20). Therefore, studying the association between miRNAs and VSMCs may comfirm whether miRNAs are biomarkers for VSMCs. miR-19a, which belongs to the miR-17-92 cluster, is an miRNA with pleiotropic functions in cancer cell survival, apoptosis and migration (21-23). However, whether miR-19a plays an important role in VSMC proliferation, migration and invasion remains unknown.

As a small GTPase, ras homolog family member B (RHOB) is the only member of the Rho family and can be modified by palmitoylation (24). RHOB has different functions, which are realized depending on its exact locations, for example, RHOB protects keratinocytes from UVB injury and RHOB determines tumor aggressiveness (25-27). RHOB is regarded as a tumor suppressor protein (28), and more importantly, a target of miRNAs in cancer $(29,30)$. In previous years, studies have increasingly suggested that activation of RHOB plays a critical role in the migration of glucose-stimulated VSMCs (31-33). Therefore, the present study investigated the effect of miR-19a on VSMC proliferation, migration and invasion, and whether RHOB is a regulatory factor of miR-19a in affecting the expression of other genes or proteins.

\section{Materials and methods}

Cell culture and transfection. A-10 cells are derived from the thoracic aorta of an embryonic rat and possess many properties of smooth muscle cells. The A-10 cell line was purchased from The American Type Culture Collection. The cells were cultured in complete growth medium with high-glucose DMEM (Gibco; Thermo Fisher Scientific, Inc.), 10\% FBS (Gibco; Thermo Fisher Scientific, Inc.), 1\% 5,000 units/ml penicillin and 5,000 $\mu \mathrm{g} / \mathrm{ml}$ streptomycin (Gibco; Thermo Fisher Scientific, Inc.). miR-19a mimics (5'-UGUGCAAAUCCAUGC AAAACUGA-3'), miR-19a inhibitor (5'-ACACGUUUAGGU ACGUUUUGACU-3') and small interfering (si)RHOB (sense, 5'-CCGUCUUCGAGAACUAUGU-3'; antisense, 5'-ACA UAGUUCUCGAAGACG G-3') were obtained from $\mathrm{OBiO}$ Technology (Shanghai) Corp., Ltd. Lipofectamine ${ }^{\circledR}$ (Gibco; Thermo Fisher Scientific, Inc.), 50 nM miR-19a mimics, $100 \mathrm{nM}$ miR-19a inhibitor and $25 \mathrm{mM}$ siRNA were diluted with FBS-free high-glucose DMEM. Lipofectamine ${ }^{\circledR}$ solution mixed with miR-19a mimics solution or miR-19a inhibitor solution or siRNA was added to the cells and incubated for 3-4 h, and the mixed solution was then replaced by complete growth medium and cultured for 24 or $48 \mathrm{~h}$.
Cell proliferation. Cell Counting Kit-8 (CCK-8) was used to measure the cell proliferation. The cells were seeded in a 96-well plate (Corning, Inc.) at a density of $5 \times 10^{3}$ cells/well and treated with mimics, inhibitor or siRNA for 24 or $48 \mathrm{~h}$. CCK-8 (Sigma-Aldrich; Merck KGaA) solution was diluted with FBS-free high-glucose DMEM at a ratio of 1:9. CCK-8 solution was added the cells for $2 \mathrm{~h}$ after the culture medium had been removed. The 96-well plate was put into a microplate reader (Thermo Fisher Scientific, Inc.), which was used to detect the optical density value at a wavelength of $490 \mathrm{~nm}$.

Cell cycle. The cells were resuspended and collected by trypsin (Gibco; Thermo Fisher Scientific, Inc.) using cold PBS (Gibco; Thermo Fisher Scientific, Inc.) and added to ethyl alcohol (Sigma-Aldrich; Merck KGaA) at $4^{\circ} \mathrm{C}$ for $12 \mathrm{~h}$. Next, the cells were centrifuged (Cence Company) at 1,000 x $\mathrm{g}$ for $5 \mathrm{~min}$ at $4^{\circ} \mathrm{C}$, PBS was added and the cells were centrifuged again at $1,000 \mathrm{x}$ g for $5 \mathrm{~min}$ at $4^{\circ} \mathrm{C}$. Propidium iodide (PI; Sigma-Aldrich; Merck KGaA) solution was added to the cells, and the cell cycle was determined using a BD FACS Calibur flow cytometer (BD Biosciences), and data were analyzed using BD CellQuest ${ }^{\mathrm{TM}}$ Pro Software version 5.1 (BD Biosciences). In total, $50 \mu \mathrm{g} / \mathrm{ml}$ PI was diluted in $0.25 \mathrm{mg} / \mathrm{ml}$ RNaseA (Sigma-Aldrich; Merck KGaA) and mixed with PBS.

Cell scratch. Cell scratching is used to assess cell migration. When the serum-starved cells filled the plate (Corning, Inc.), a 200- $\mu$ l pipette tip (Sigma-Aldrich; Merck KGaA) was used to scratch the cells, which were then washed with PBS twice, and the location and images were recorded. The images were taken using a light microscope (Olympus Corporation; magnification, $x 200)$. The wound width was calculated using the following formula: Wound width=(width of $24 \mathrm{~h}$ or $0 \mathrm{~h}) /($ width of $0 \mathrm{~h}$ in the Control group) $\mathrm{x} 100$.

Transwell Matrigel assay. A Transwell Matrigel assay is performed to assess cell invasive ability. Matrigel (Sigma-Aldrich; Merck KGaA) was diluted with FBS-free high-glucose DMEM (Gibco; Thermo Fisher Scientific, Inc.) at a ratio of 1:8. The Matrigel solution was placed in the top of the Transwell plate (Corning, Inc.) in an incubator (Thermo Fisher Scientific, Inc.) at $37^{\circ} \mathrm{C}$ and incubated for $6 \mathrm{~h}$. The top of the Transwell plate was then washed with FBS-free high-glucose DMEM three times. The cells were resuspended by centrifugation (Cence Company; $1,000 \mathrm{x} \mathrm{g}$ ) at $4^{\circ} \mathrm{C}$ for $10 \mathrm{~min}$ with FBS-free high-glucose DMEM after the treatment with mimics, inhibitor or siRNA. Next, the cells $\left(1 \times 10^{5}\right)$ were added to the upper chamber of the Transwell plate, while high-glucose DMEM with $20 \%$ FBS was added to the lower chamber. The cells in the Transwell plate were incubated in an incubator at $37^{\circ} \mathrm{C}$ for $24 \mathrm{~h}$. The cells in the upper chamber of the Transwell plate were removed, fixed with $10 \%$ methanol (Thermo Fisher Scientific, Inc.) for $30 \mathrm{~min}$ at $4^{\circ} \mathrm{C}$, whereas those in the lower chamber of the Transwell plate were stained using crystal violet (Beijing Solarbio Science \& Technology Co., Ltd.) for $30 \mathrm{~min}$ at $37^{\circ} \mathrm{C}$. The images of the invaded cells were taken using a light microscope (Olympus Corporation; magnification, x200). The invasion rate was calculated using the following formula: Invasion rate, $\%=$ (the amount of invasive cells)/(the amount of invasive cells in the Control group) $\mathrm{x} 100$. 
Dual luciferase assay. TargetScan 7.2 (www.targetscan. org) was used to identify three potential targets of miR-19a. The wild-type RHOB 3'UTR or mutant RHOB 3'UTR were cloned into psi-CHECK-2 (Promega Corporation). The cells were transfected by carrier material with the target gene using Lipofectamine $^{\circledR}$ (Gibco; Thermo Fisher Scientific, Inc.) for $6 \mathrm{~h}$. The fluorescence was detected using a Dual Luciferase Reporter Gene Detection kit (Beijing Solarbio Science \& Technology Co., Ltd.) $24 \mathrm{~h}$ after transfection, according to the manufacturer's protocol. Firefly luciferase activity was normalized to Renilla luciferase activity.

Western blotting. Cell lysis buffer (Thermo Fisher Scientific, Inc.) was used to extract total protein, the concentration of which was detected using a bicinchoninic assay kit (Thermo Fisher Scientific, Inc.) according to the manufacturer's protocol. An equal amount of protein $(20 \mu \mathrm{g})$ was loaded and added to an $12 \%$ SDS-PAGE machine (Bio-Rad Laboratories, Inc.) to be separated. Next, the protein was transferred to PVDF membranes (Sigma-Aldrich; Merck KGaA) by cataphoresis. 5\% bovine serum albumin (Sigma-Aldrich; Merck KGaA) was used to block the blank site of the membranes at $37^{\circ} \mathrm{C}$ for $30 \mathrm{~min}$, which were subsequently incubated with antibodies against dual specificity phosphatase Cdc25A (CDC25A; cat. no. ab2357; Abcam; 1:1,000), cyclinD1 (cat. no. ab134175; Abcam; 1:1,000), matrix metalloproteinase (MMP)-2 (cat. no. ab37150; Abcam; 1:1,000), MMP-9 (cat. no. ab73734; Abcam; 1:1,000), $\alpha$-smooth muscle actin ( $\alpha$-SMA; cat. no. ab5694; Abcam; 1:1,000), smooth muscle $22 \alpha$ (SM22 $\alpha$; cat. no. ab14106; Abcam; 1:1,000), RHOB (cat. no. ab155149; Abcam; 1:1,000) and GAPDH (cat. no. ab8245; Abcam; 1:5,000) overnight at $4^{\circ} \mathrm{C}$. TBS with Tween-20 (Beijing Solarbio Science \& Technology Co., Ltd.) was used to wash the membranes three times. The membranes were incubated with a secondary antibody (cat. no. ab7090; Abcam; 1:5,000) at room temperature for 2-3 $\mathrm{h}$ and stained using an ECL kit (Sigma-Aldrich; Merck KGaA). The western blots were analyzed using Bio-Rad ChemiDoc ${ }^{\mathrm{TM}}$ XRS+ System with Image Lab $^{\mathrm{TM}}$ Software version 4.1 (Bio-Rad Laboratories, Inc.).

Reverse transcription-quantitative PCR (RT-qPCR). Total RNA was extracted with TRIzol ${ }^{\circledR}$ (Sigma-Aldrich; Merck $\mathrm{KGaA}$ ) by centrifuging the cells at $6,500 \mathrm{x} \mathrm{g}$ for $10 \mathrm{~min}$ at $4^{\circ} \mathrm{C}$. The Sensiscript RT kit (Promega Corporation) was used to synthesize cDNA at $45^{\circ} \mathrm{C}$ for $15 \mathrm{~min}$ and at $95^{\circ} \mathrm{C}$ for $3 \mathrm{~min}$. The amplification reactants were cDNA, $\mathrm{ddH}_{2} \mathrm{O}$, forward primer, reverse primer and Fast SYBR-Green Master mix (Thermo Fisher Scientific, Inc.).

The primer sequences used were as follows: miR-19a (forward: 5'-GTTTTGCATAGTTGCACTA-3'; reverse: 5'-GAACATGTCTGCGTATCTC-3') MMP-2 primer (forward: 5'-TTCCCCCGCAAGCCCAAGTG-3'; reverse: 5'-GAGAAAAGCGCAGCGGAGTGACG-3'); MMP-9 primer (forward: 5'-CACCACCACAACTGAACC-3'; reverse: 5'-GCC TAGACCCAACTTATCC-3'); $\alpha$-SMA primer (forward: 5'-AGCCAGTCGCCATCGGAAC-3'; reverse: 5'-CCGGAG CCATTGTCACACAC-3'); SM22 $\alpha$ primer (forward: 5'-TTC TGCCTCAACATGGCCAAC-3'; reverse: 5'-CACCTTCAC TGGCTTGGATC-3'); RHOB primer (forward: 5'-TGCTGA
TCGTGTTCAGTAAG-3'; reverse: 5'-AGCACATGAGAA TGACGTCG-3'); suppressor of cytokine signaling 3 (SOCS3) primer (forward: 5'-CCCAAGCTTATGGTCACCCAC AGC-3'; reverse: 5'-CGCGGATCCTACTGGTCCAGG-3'); T-cell intracellular antigen-1 (TIA1) primer (forward: 5'-CAG ATGGGTGGCCAGTGGCT-3'; reverse: 5'-TGACCTTCA ATGGTAGTACCA-3'); cyclinD1 primer (forward: 5'-GTA GCAGCGAGCAGCAGAGT-3'; reverse: 5'-CTCCTCGCA CTTCTGTTCCTC-3'); CDC25A primer (forward: 5'-CCA AAGGAACCATTGAGAAC-3'; reverse: 5'-CAGATGCCA TAATTTCTGGAG-3'); and U6 primer as the loading control (forward: 5'-TGAGAACTGAATTCCATGGGTT-3'; reverse: 5'-ACGCTTCACGAATTTGCGT-3'). The conditions of the PCR amplification were $95^{\circ} \mathrm{C}$ for $30 \mathrm{sec}$, followed by 40 cycles of $95^{\circ} \mathrm{C}$ for $30 \mathrm{sec}$ and $75^{\circ} \mathrm{C}$ for $15 \mathrm{sec}$. The relative level of mRNA was determined using the $2^{-\Delta \Delta \mathrm{Cq}}$ method (34).

Statistical analysis. Each experiment was repeated three time. Data are presented as the mean \pm SD and were analyzed by SPSS 16.0 software (SPSS, Inc.) using ANOVA with Turkey's multiple comparisons test. $\mathrm{P}<0.05$ was considered to indicate a statistically significant difference.

\section{Results}

miR-19a promotes VSMC proliferation and cell cycle. To validate the roles of miR-19a in VSMCs, miR-19a mimics and inhibitor were transfected into VSMCs to increase or decrease miR-19a levels, respectively ( $\mathrm{P}<0.05$; Fig. 1A). The effects of miR-19a on the proliferation of VSMCs were subsequently determined. It was observed that elevated miR-19a significantly increased the proliferation of VSMCs, while downregulated miR-19a noticeably repressed the proliferation ( $\mathrm{P}<0.05$; Fig. 1B). The cell cycle of the VSMCs was analyzed by flow cytometry, as shown in Fig. $1 C$ and $D$, the proportion of cells in the $G_{1}$ phase was notably reduced from $56.55 \%$ in the mimic control group to $47.67 \%$ in the mimic group, while the number of cells in the $\mathrm{G}_{2}$ phase increased from $17.63 \%$ in the mimic control group to $29.92 \%$ in the mimic group $(\mathrm{P}<0.05)$. By contrast, the numbers of cells in the $\mathrm{G}_{1}$ phase was notably increased from $58.68 \%$ in the inhibitor control group to $72.68 \%$ in the inhibitor group, while those in the $\mathrm{G}_{2}$ phase decreased from $16.4 \%$ in the inhibitor control group to $9.97 \%$ in the inhibitor group $(\mathrm{P}<0.05)$. The present results suggested that overexpression of miR-19a could promote the cell cycle, while inhibition of miR-19a could induce $\mathrm{G}_{1}$ cell cycle arrest. To further explore the effect of miR-19a on the cell cycle, the expressions of CDC25A and cyclinD1 at the mRNA and protein levels were determined; it was demonstrated that upregulation of miR-19a increased the mRNA and protein expressions of CDC25A and cyclinD1, which were repressed by the inhibitor $(\mathrm{P}<0.05$; Fig. 2).

miR-19a promotes the migration and invasion of VSMCs. The shortest distance of a scratch was observed in the cells transfected with miR-19a mimics for $24 \mathrm{~h}(\mathrm{P}<0.05$; Fig. 3A and $\mathrm{B})$. Moreover, the proportion of invasive cells in the miR-19a mimics group was higher than the control group, and the cells treated with miR-19a inhibitor had a lower rate of invasion $(\mathrm{P}<0.05$; Fig. 3C and D), suggesting that miR-19a promoted the invasion of VSMCs. 

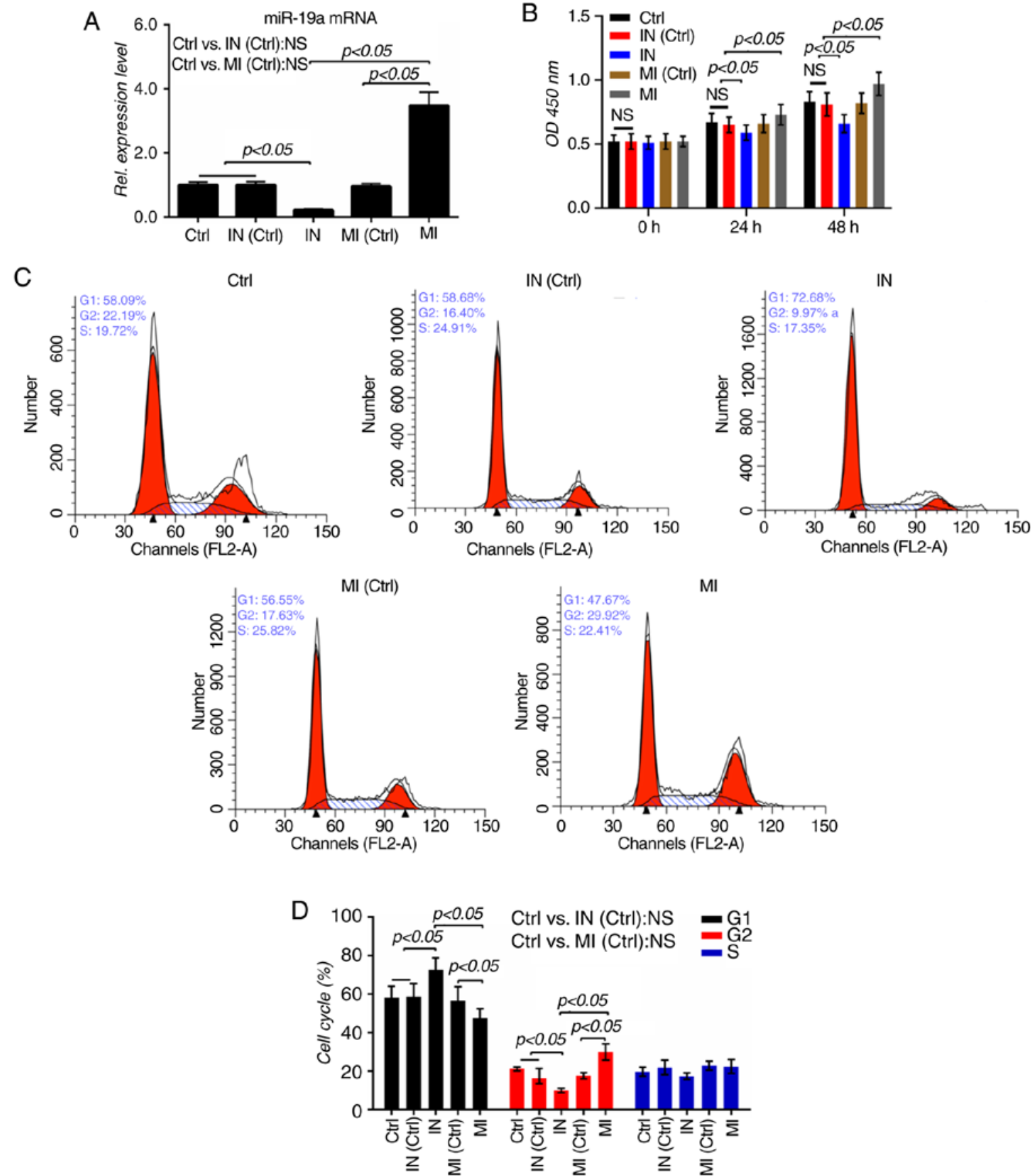

Figure 1. miR-19a promotes VSMC proliferation. (A) miR-19a mimics or miR-19a inhibitor were transfected into the VSMCs and cultured for $24 \mathrm{~h}$. Reverse transcription-quantitative PCR detected the miR-19a mRNA in VSMCs. (B) Cell Counting Kit- 8 detected the proliferation of VSMCs transfected with miR-19a mimics or miR-19a inhibitor for 24 or $48 \mathrm{~h}$ using a microplate reader at a wavelength of $490 \mathrm{~nm}$. miR-19a mimics or miR-19a inhibitor were transfected into VSMCs and cultured for $48 \mathrm{~h}$. A propidium iodide kit assessed the cell cycle by (C) flow cytometry and (D) subsequent analysis. The images of the peaks were analyzed using a flow cytometry system. All values are presented as the mean \pm SD. The data were analyzed by ANOVA with Turkey's multiple comparisons test. miR, microRNA; VSMC, vascular smooth muscle cell; MI, miR-19a mimics; IN, miR-19a inhibitor; Ctrl, control; Rel., relative; NS/ns, not significant; OD, optical density.

To verify the role of miR-19a in the migration and invasion of VSMCs, the expressions of several related molecules were additionally detected. It was observed that the miR-19a mimics significantly upregulated the mRNA levels of MMP-2, MMP-9, $\alpha$-SMA and SM22 $\alpha$, and that the miR-19a inhibitor exerted an opposite effect on these mRNAs ( $\mathrm{P}<0.05$; Fig. 4A-D). Also, the protein levels of MMP-2, MMP-9, $\alpha$-SMA and SM22 $\alpha$ were similar to the mRNA expressions of those molecules $(\mathrm{P}<0.05$; Fig. 4E and F).
RHOB is a direct target of miR-19a.TIA1, RHOB and SOCS3 were identified as three potential targets of miR-19a. Although miR-19a did not affect the level of TIA1, overexpression of miR-19a inhibited the expressions of RHOB and SOCS3, and downregulation of miR-19a increased the levels of RHOB and SOCS3, and the effect of miR-19a on RHOB was more marked compared with SOCS3 ( $\mathrm{P}<0.05$; Fig. 5A). Therefore, it was predicted that RHOB is a potential target of miR-19a, and the potential binding site of miR-19a was identified in 
A

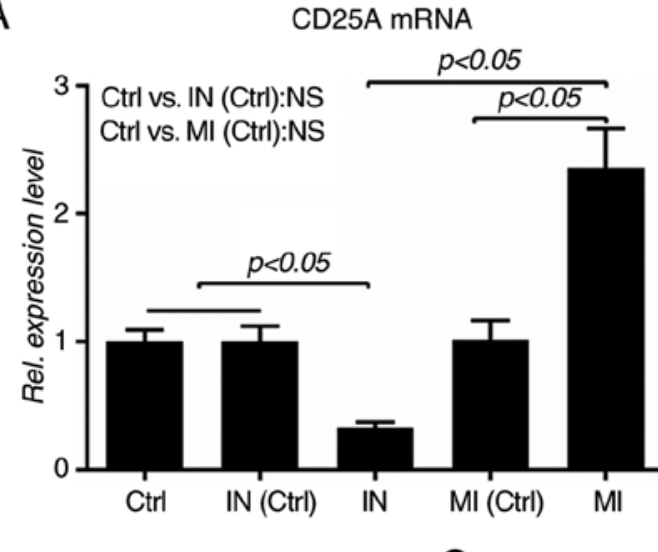

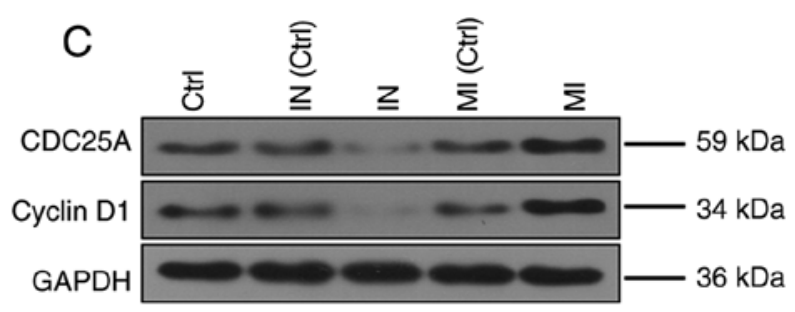

D

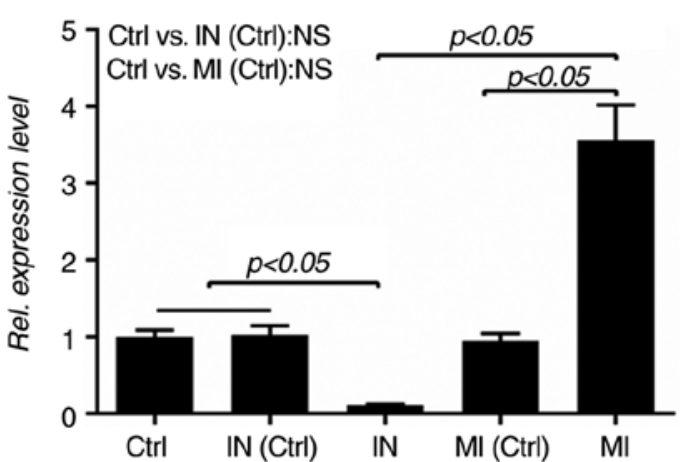

B

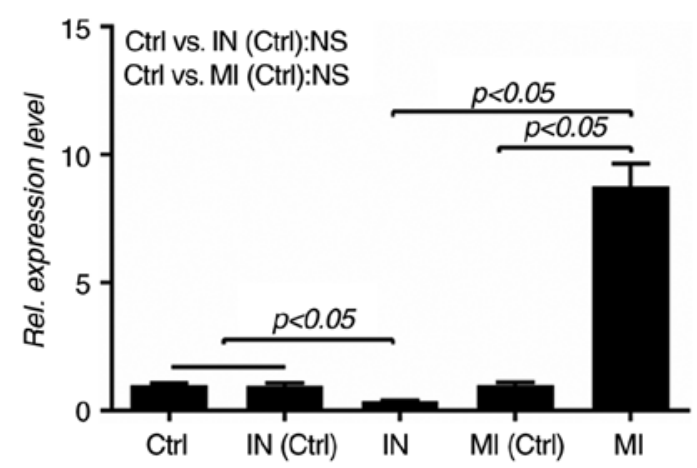

Cyclin D1 mRNA
$\mathrm{E}$

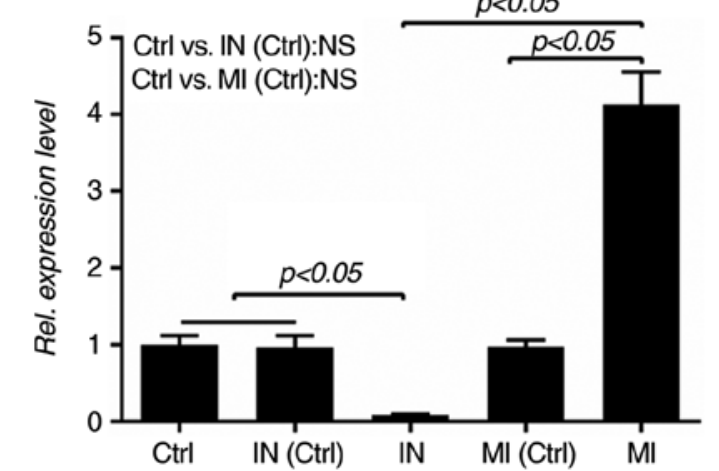

Figure 2. miR-19a increases the expressions of CDC25A and cyclinD1 in VSMCs. miR-19a mimics or miR-19a inhibitor were transfected into VSMCs and cultured for $48 \mathrm{~h}$. Reverse transcription-quantitative PCR measured the mRNA levels of (A) CDC25A and (B) cyclinD1. (C) Western blotting and subsequent analysis determined the protein levels of (D) CDC25A and (E) cyclinD1. All values are presented as the mean \pm SD. The data were analyzed by ANOVA with Turkey's multiple comparisons test. miR, microRNA; CDC25A, dual specificity phosphatase Cdc25A; VSMCs, vascular smooth muscle cells; MI, miR-19a mimics; IN, miR-19a inhibitor; Ctrl, control; Rel., relative; NS, not significant.

the 3'-UTR of RHOB mRNA (Fig. 5B). Additionally, the luciferase activity of the wild-type RHOB-3'-UTR was significantly lower in the miR-19a group than in the control group $(\mathrm{P}<0.05)$; however, it was significantly increased by the inhibitor $(\mathrm{P}<0.05$; Fig. $5 \mathrm{C})$.

To further explore the role of RHOB in VSMCs, RHOB expression was silenced using siRNA. RHOB expression was significantly suppressed by siRNA, and the proliferation of VSMCs was significantly increased by the siRHOB $(\mathrm{P}<0.05$; Fig. 5D and E). To further confirm that RHOB was a direct target gene of miR-19a, VSMCs were co-transfected with inhibitor and siRHOB. The results showed that the mRNA expression of RHOB was increased by the inhibitor $(\mathrm{P}<0.05)$; however, the inhibitor showed no effect on the expression in the siRHOB group (Fig. 5F). Furthermore, the present data demonstrated that the protein levels of RHOB in the inhibitor group were significantly upregulated, and that the inhibitor could increase the low expression of RHOB caused by siRNA $(\mathrm{P}<0.05$; Fig. 5G).
RHOB suppression restores the inhibitory effects of $m i R-19 a$ inhibitor in VSMCs. The results of the CCK-8 assay demonstrated that co-transfection of miR-19a inhibitor and siRHOB could increase the proliferation of VSMCs, compared with the inhibitor group $(\mathrm{P}<0.05$; Fig. 6A). As RHOB serves a direct role in the migration of VSMCs (31), the role of RHOB in the regulatory effect of miR-19a inhibitor in VSMCs was investigated. The scratch width in the co-transfection group was longer than that in the siRHOB group $(\mathrm{P}<0.05)$ but slightly shorter than the inhibitor group ( $\mathrm{P}>0.05$; Fig. $6 \mathrm{~B}$ and $\mathrm{C})$. Furthermore, the invasive cells in the co-transfection group significantly increased compared with the inhibitor group $(\mathrm{P}<0.05$; Fig. 6D and $\mathrm{E})$.

To further explore the effect of RHOB on the migration and invasion of VSMCs, the expressions of molecules associated with migration and invasion were detected. Compared with the inhibitor group, the co-transfection group showed significantly increased $\mathrm{mRNA}$ expressions of MMP-2, MMP-9, $\alpha$-SMA and SM22 $\alpha$ (P<0.05; Fig. 7A-D). 
A
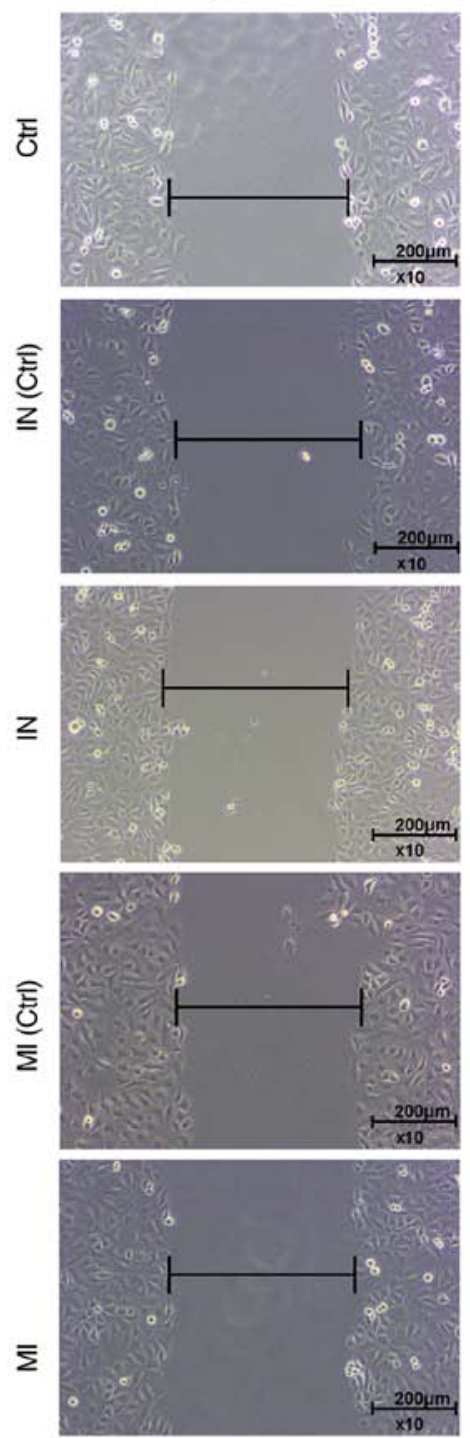

$24 \mathrm{~h}$
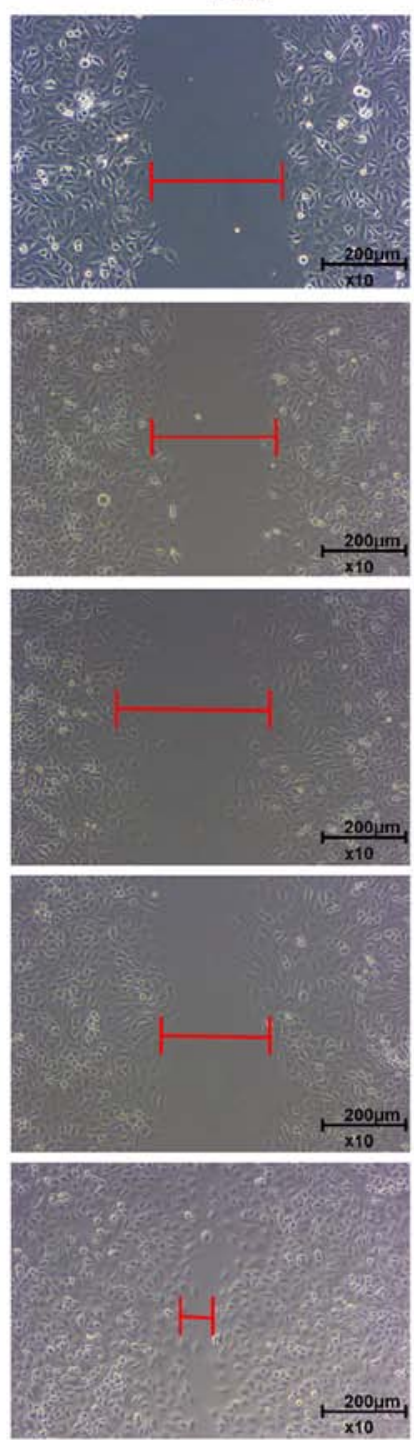
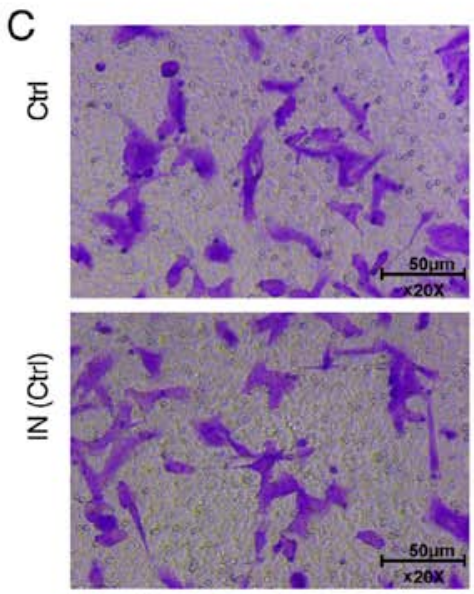

$\underline{z}$
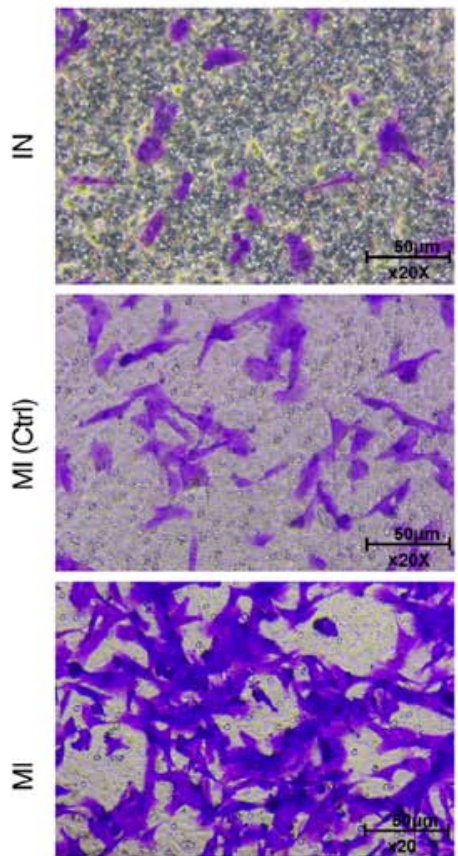

$\mathrm{B}$
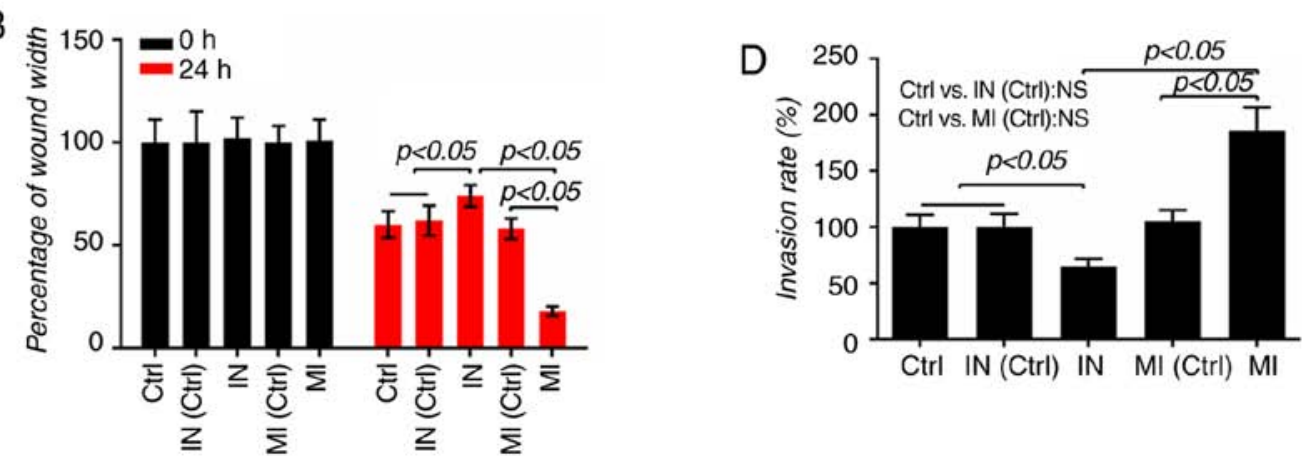

Figure 3. miR-19a promotes VSMC migration and invasion. miR-19a mimics or miR-19a inhibitor were transfected into VSMCs and cultured for 48 h. VSMCs were seeded in a plate for $24 \mathrm{~h}$. A pipette tip was used to scratch the plate, and the images were taken using a microscope. After $24 \mathrm{~h}$, the scratches were observed again. (A) Representative images and (B) subsequent analysis are presented. Matrigel was used in a Transwell assay to detect cell invasion. (C) Representative images of cells stained with crystal violet and (D) subsequent analysis are presented. All values are presented as the mean \pm SD. The data were analyzed by ANOVA with Turkey's multiple comparisons test. miR, microRNA; VSCM, vascular smooth muscle cell; MI, miR-19a mimics; IN, miR-19a inhibitor; Ctrl, control; NS, not significant.

Moreover, the changes at the protein level in each group were similar to those of mRNA, except SM22 $\alpha$, as the protein level of SM22 $\alpha$ in the co-transfection group exhibited a slight increase in comparison with the inhibitor group (Fig. 7E-I).

\section{Discussion}

The present study is the first, to the best of the authors' knowledge, to demonstrate that miR-19a promoted VSMC proliferation, migration and invasion, although VSMC 

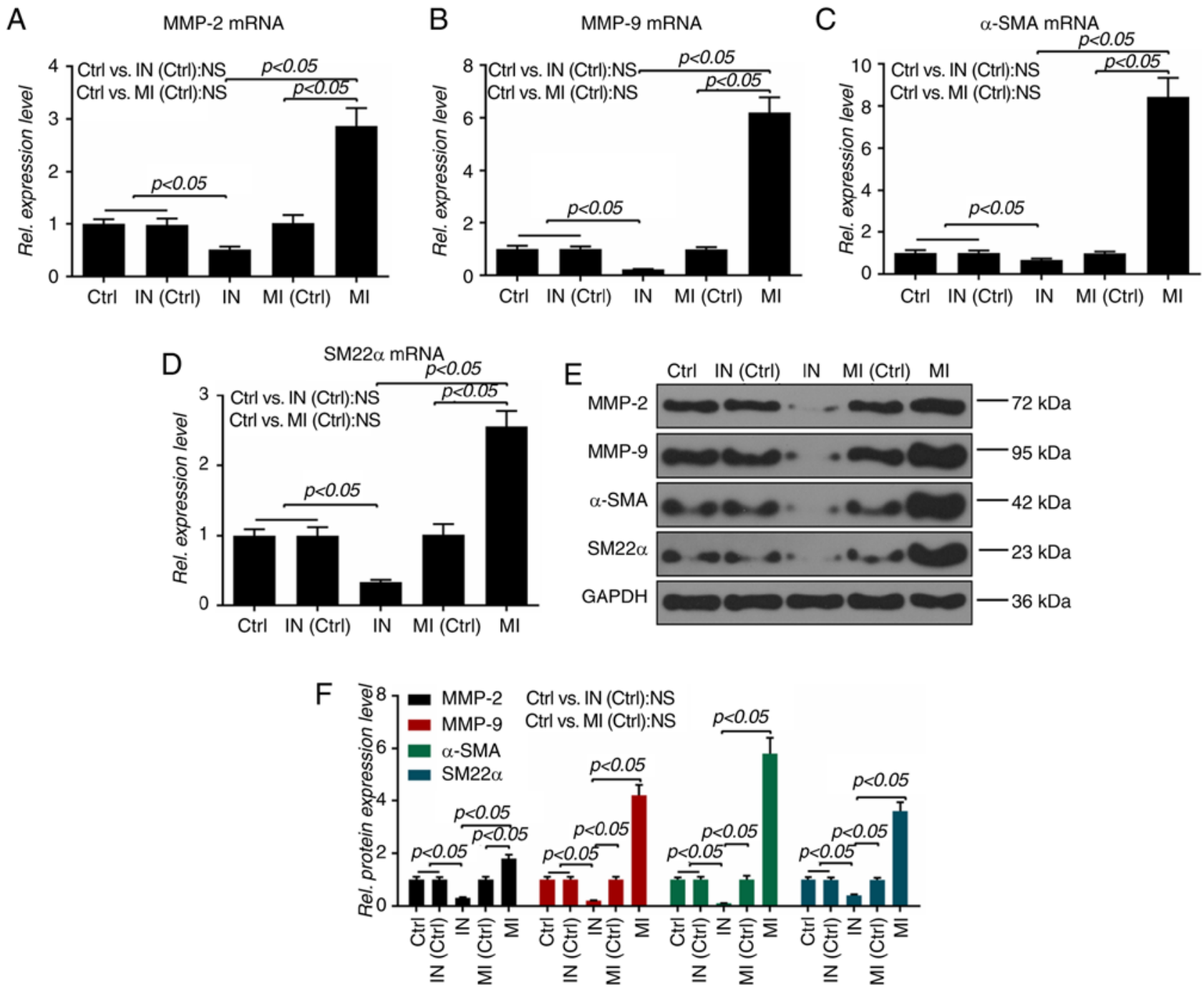

Figure 4. Effect of microRNA-19a on migration-related molecules. The mRNA levels of (A) MMP-2, (B) MMP-9, (C) $\alpha-S M A$ and (D) SM22 $\alpha$ were measured by reverse transcription-quantitative PCR. Protein levels of MMP-2, MMP-9, $\alpha$-SMA and SM22 $\alpha$ were determined by (E) western blotting and (F) densitometry. All values are presented as the mean \pm SD. The data were analyzed by ANOVA with Turkey's multiple comparisons test. MMP, matrix metalloproteinase; $\alpha$-SMA, $\alpha$-smooth muscle actin; SM22 $\alpha$, smooth muscle 22 $\alpha$; MI, microRNA-19a mimics; IN, microRNA-19a inhibitor; Ctrl, control; Rel. relative; NS, not significant.

proliferation is implicated in atherogenesis. Moreover, miR-19a contributed to the growth of VSMCs by promoting $\mathrm{G}_{2}$ cell generation. The effect of miR-19a on the expressions of related proteins or genes was also investigated.

CDK activation and inactivation play a key role in cell cycle progression (35). CDK activation, a critical step in the cell cycle, is realized by inhibiting CDK phosphorylation through the CDC25 family dual-specificity phosphatases. CDC25 isoforms include CDC25A, CDC25B and CDC25C in mammals (36), and CDC25A has the most important function of the CDC25 isoforms, and a defect in CDC25A is lethal in early stages of embryogenesis, indicating that CDC25A plays an indispensable role in cell division (37). CDC25A activates Cyclin A/E to accelerate $\mathrm{G}_{1} / \mathrm{S}$ transition (38). Moreover, CDC25A also contributes to Cyclin B contribution in $\mathrm{G}_{2} / \mathrm{M}$ transition (39). Cell mitosis requires cells to leave the resting state $\left(\mathrm{G}_{0} / \mathrm{G}_{1}\right)$ and proceed to the phase of DNA synthesis (S) and mitosis $\left(\mathrm{G}_{2} / \mathrm{M}\right)$. Noticeably, there is a critical moment between $G_{0} / G_{1}$ and $S$, during which, cyclinD1, an important cyclin, allows cells to get through the critical moment between
$\mathrm{S}$ and $\mathrm{G}_{2} / \mathrm{M}$ (40). A higher cyclinD1 expression can promote cell proliferation (41). The present data showed that miR-19a altered cell cycle progression by upregulating cyclinD1 and CDC25A expressions.

MMPs are a large family, in which zinc-dependent and calcium-dependent endopeptidases are responsible for degrading multiple extracellular matrix proteins (42). MMP-2 and MMP-9, two gelatin enzyme subgroups of MMP, have the ability to hydrolyze the basement membrane and have been regarded as key molecules involved in cell metastasis, migration and invasion (43-46). Encoded by the actin $\alpha 2$, smooth muscle, $\alpha$-SMA is an isoform of vascular smooth muscle actin, which is typically expressed in VSMCs and contributes to vascular cell motility and contraction (47). SM22 $\alpha$, an actin-binding protein, is abundant in smooth muscle cells of vertebrates (48). Yuan (47) demonstrated that SM22 $\alpha$ accelerated actin filament assembly into bundles, which possibly enhanced VSMC contractility and mobility, and SM22 $\alpha$ activation helped balance the VSMC differentiated phenotype. In the present study, inhibition of RHOB 
A

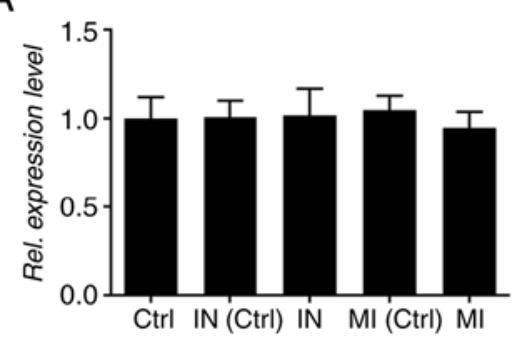

Rhob mRNA

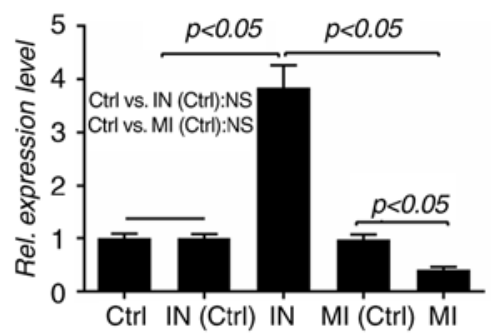

SOCS3 mRNA

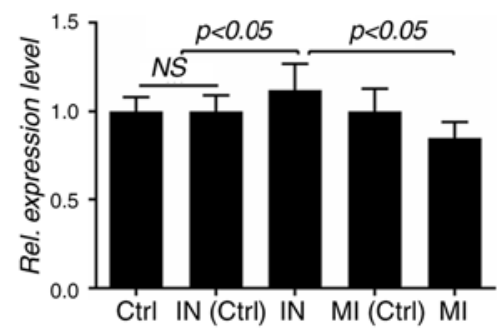

B

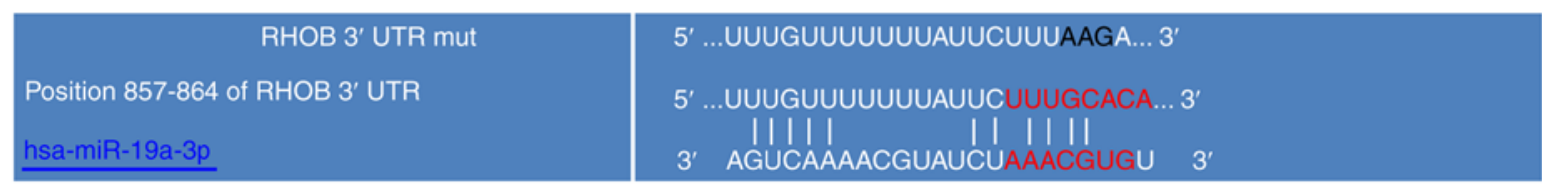

C

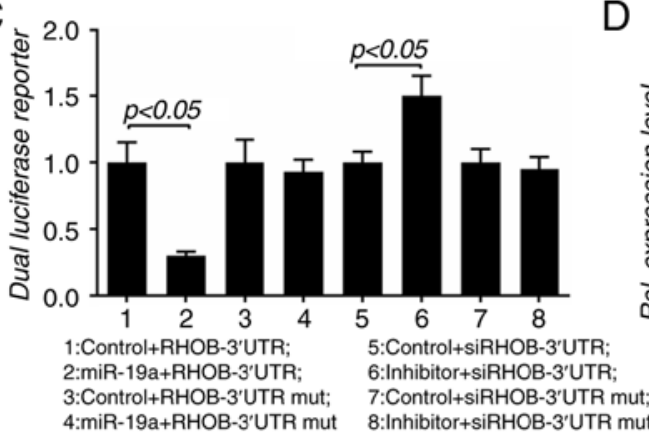

RHOB mRNA

F

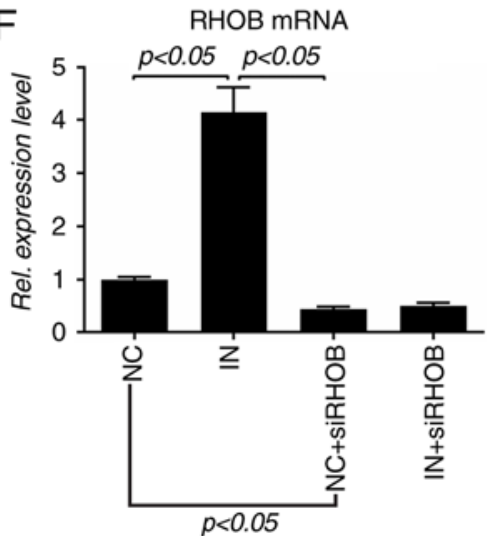

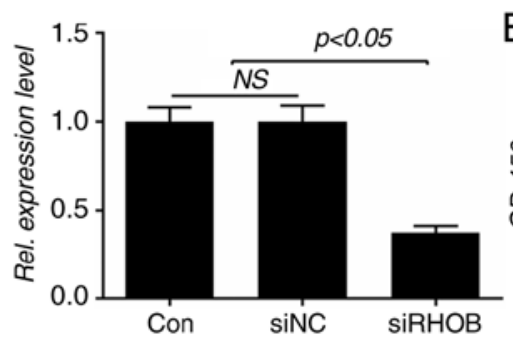

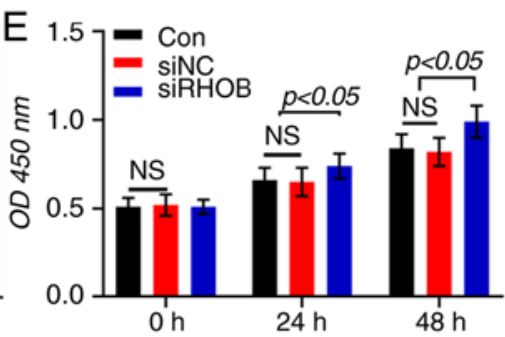

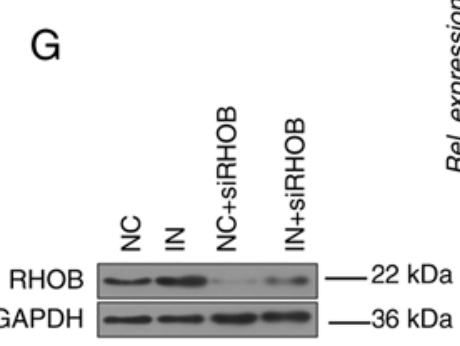

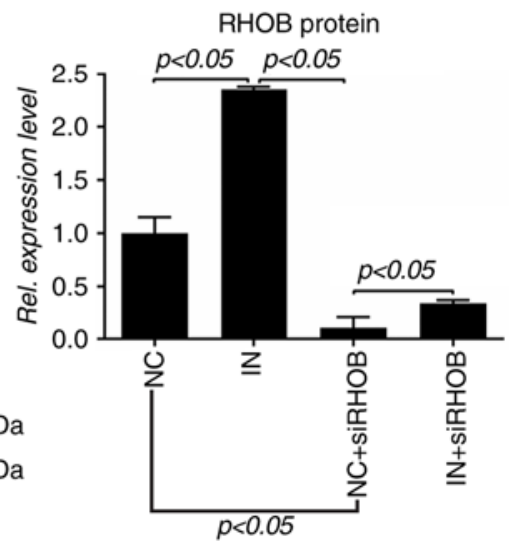

Figure 5. RHOB is a direct target gene of miR-19a in VSMCs. (A) mRNA levels of TIA1, RHOB and SOCS3 were measured by RT-qPCR. (B) Possible miR-19a binding site in the 3'-UTR of RHOB mRNA was predicted using TargetScan7.2. (C) A dual-luciferase reporter assay was performed to analyze the relative luciferase activity in VSMCs. VSMCs were transfected in 24-well plates with the indicated luciferase reporter plasmid or its mutant. VSMCs were also co-transfected with miR-19a mimics, inhibitor or corresponding control. At $48 \mathrm{~h}$ post-transfection, the luciferase activities were measured using a microplate reader with a dual luciferase kit. (D) mRNA expression of RHOB in VSMCs transfected with siRHOB or negative control was analyzed by RT-qPCR (E) Proliferation of VSMCs was detected by a Cell Counting Kit-8 assay using a microplate reader at $490 \mathrm{~nm}$. (F) mRNA and (G) protein expressions of RHOB in VSMCs transfected with inhibitor and siRNAs were determined by RT-qPCR and western blotting, respectively. All values are presented as the mean \pm SD. The data were analyzed by ANOVA with Turkey's multiple comparisons test. RHOB, Ras homolog family member B; miR, microRNA; VSMC, vascular smooth muscle cell; TIA1, T-cell intracellular antigen-1; SOCS3, suppressor of cytokine signaling 3; RT-qPCR, reverse transcription-quantitative PCR; 3'UTR, 3' untranslated region; si, small interfering; Ctrl/Con, control; MI, miR-19a mimics; IN, miR-19a inhibitor; NS/ns, not significant; Rel., relative; $\mathrm{NC}$, negative control; OD, optical density; mut, mutant.

promoted VSMC proliferation, invasion and migration, and partly reversed the inhibitory effect of the miR-19a inhibitor on VSMC proliferation, invasion and migration. miR-19a increased VSMC migration and invasion by promoting the MMP/ $\alpha$-SMA/SM22 $\alpha$ signaling pathway. Moreover, inhibited RHOB also promoted the MMP/ $\alpha$-SMA/SM $22 \alpha$ signaling pathway, suggesting that the signaling pathway could be affected through RHOB.
SOCS3 inactivation was shown to enhance the cell survival signaling pathway (49). A previous study demonstrated that SOCS3 was a target of miR-19a, in which miR-19a could promote rheumatoid arthritis fibroblast-like synoviocytes by targeting SOCS3 (50). miR-19a can also enhance the proliferation and insulin secretion of pancreatic $\beta$ cells, and inhibit the apoptosis of pancreatic $\beta$ cells by targeting SOCS3 (51). In the present study, overexpression 

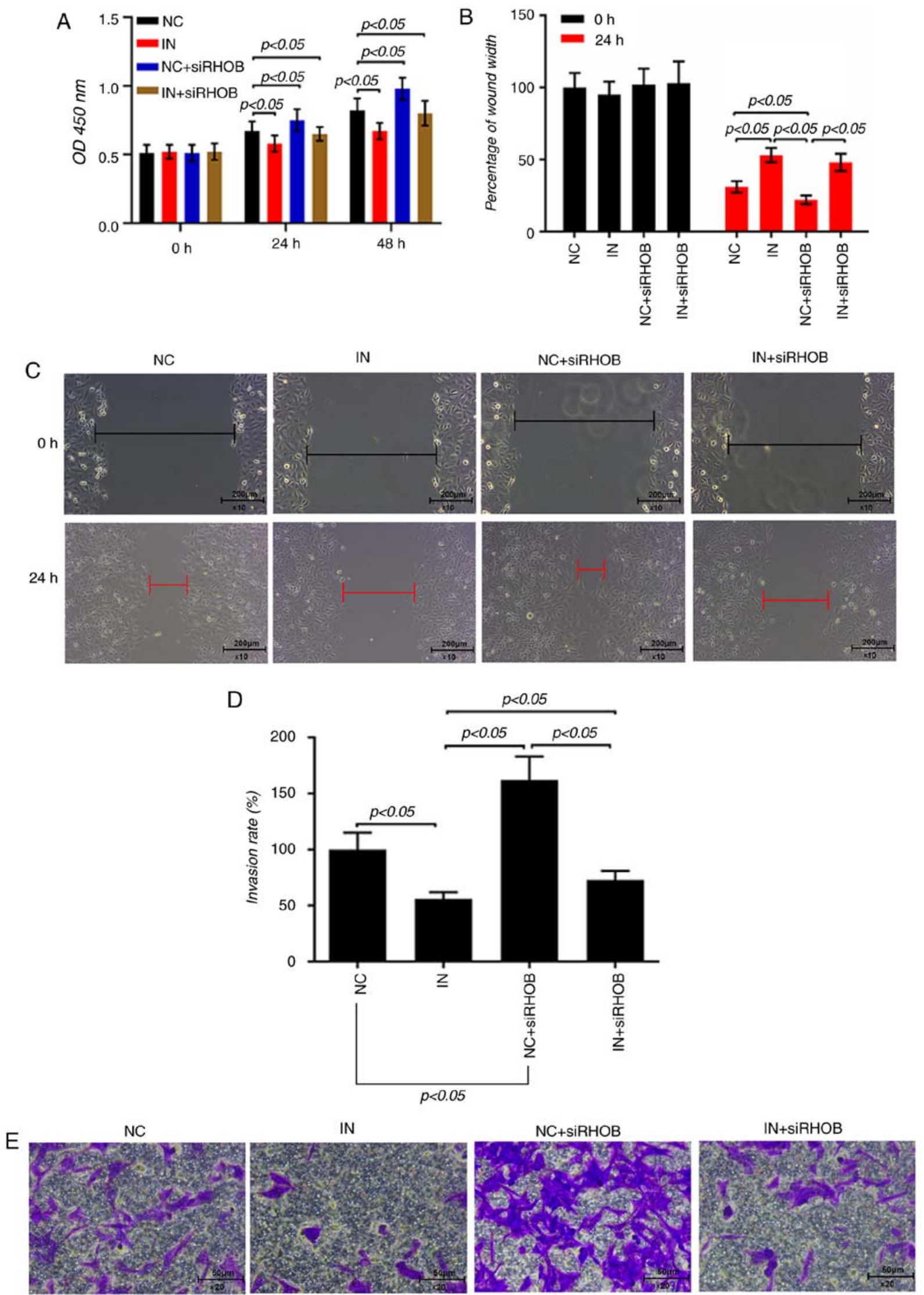

Figure 6. Inhibition of RHOB restores miR-19a inhibitor-induced inhibitory effects on VSMC proliferation, migration and invasion. (A) miR-19a inhibitor and siRHOB alone or in combination were transfected into the VSMCs and cultured for $48 \mathrm{~h}$. Cell proliferation was measured by a Cell Counting Kit- 8 assay. A wound-healing assay was performed in VSMCs that had been transfected with inhibitor and siRHOB, and the relative wound width was measured. (B) Percentage of wound width and (C) representative images are presented. A transwell Matrigel assay was used in VSMCs that had been treated with inhibitor and siRHOB, and the invasion rate was calculated. (D) Invasion rate and (E) representative images of cells stained with crystal violet are presented. All values are presented as the mean $\pm \mathrm{SD}$. The data were analyzed by ANOVA with Turkey's multiple comparisons test. RHOB, Ras homolog family member B; miR, microRNA; VSMC, vascular smooth muscle cell; si, small interfering; MI, miR-19a mimics; IN, miR-19a inhibitor; NC, negative control; OD, optical density. 
A

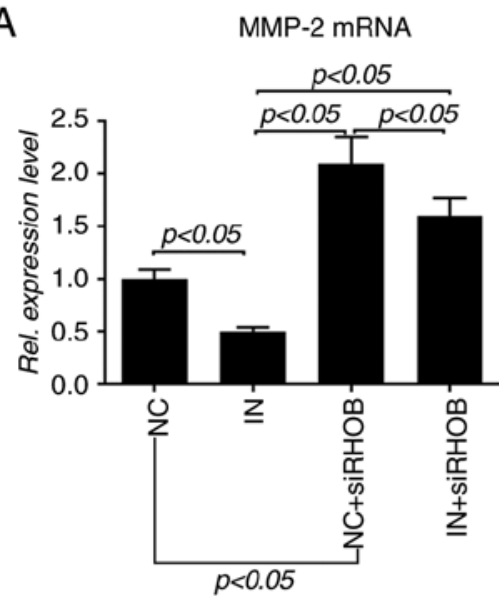

D

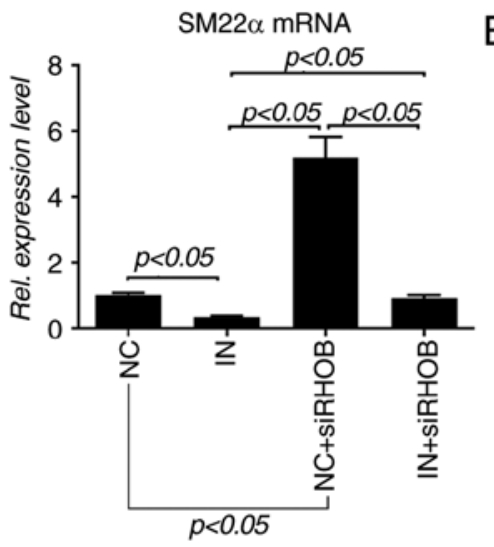

G

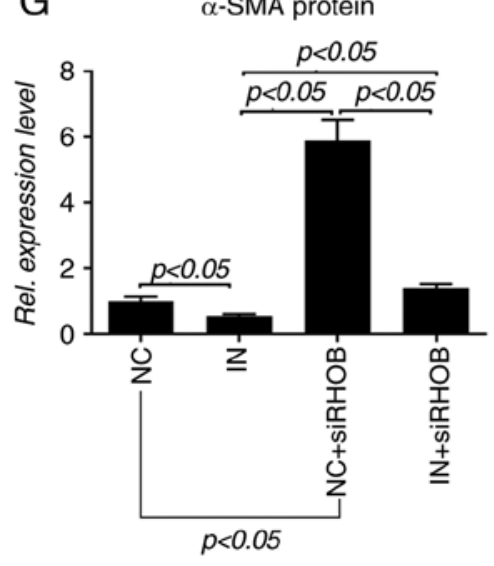

B

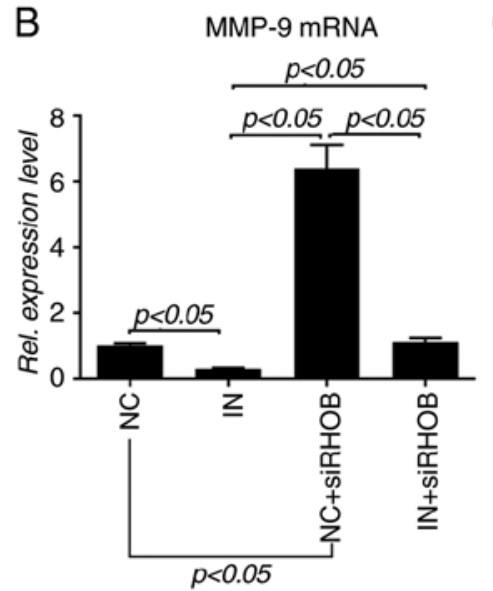

E

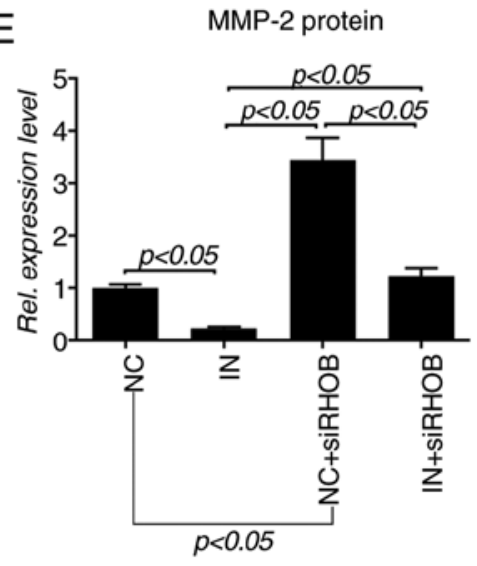

$\mathrm{H}$

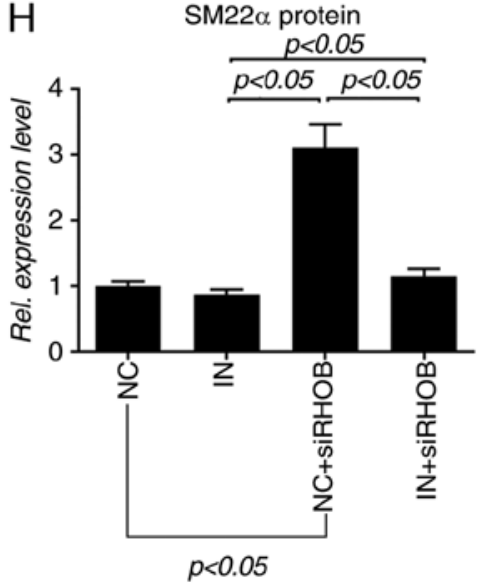

C

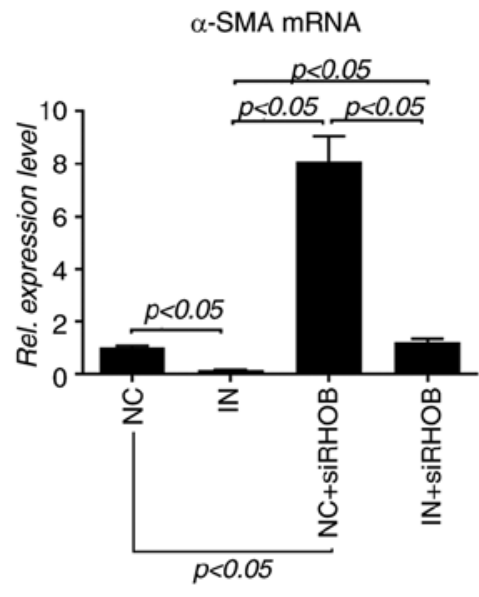

$\mathrm{F}$

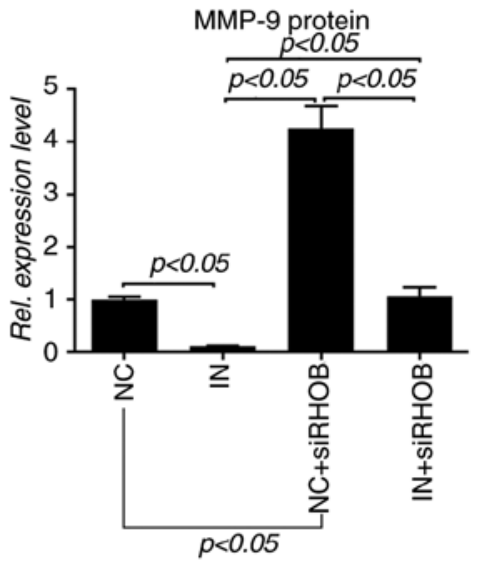

I

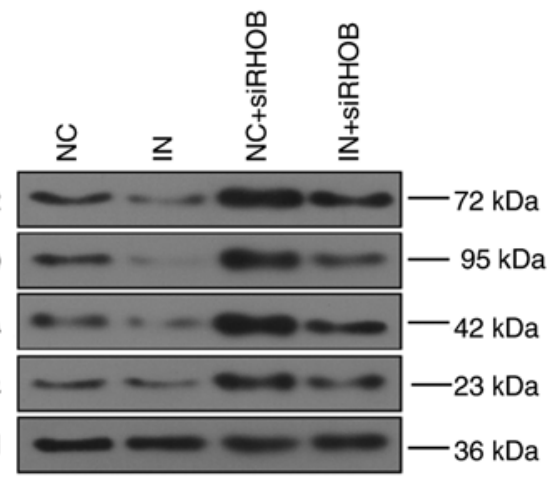

Figure 7. Inhibition of RHOB restores miR-19a inhibitor-induced inhibitory effects on molecules related to migration and invasion in VSMCs. miR-19a inhibitor and siRHOB alone or in combination were transfected into the VSMCs and cultured for $48 \mathrm{~h}$. The mRNA levels of (A) MMP-2, (B) MMP-9, (C) $\alpha-S M A$ and (D) SM22 $\alpha$ were measured by reverse transcription-quantitative PCR. The protein levels of (E) MMP-2, (F) MMP-9, (G) $\alpha$-SMA and (H) SM22 $\alpha$ were detected and determined by (I) western blotting followed by densitometry analysis. All values are presented as the mean \pm SD. The data were analyzed by ANOVA with Turkey's multiple comparisons test. RHOB, Ras homolog family member B; miR, microRNA; VSMC, vascular smooth muscle cell; si, small interfering; MMP, matrix metalloproteinase; $\alpha$-SMA, $\alpha$-smooth muscle actin; SM22 $\alpha$, smooth muscle 22 $\alpha$; IN, miR-19a inhibitor; NC, negative control; Rel., relative.

of miR-19a suppressed the SOCS3 level, while inhibition of miR-19a increased SOCS3 expression. However, the effect of miR-19a on SOCS3 was weaker than that on RHOB, suggesting that SOCS3 may play a less crucial role in the proliferation, migration and invasion of VSMCs. As a DNA/RNA binding protein, TIA1 is associated with granules of cytolytic lymphocytes and apoptosis by DNA fragmentation (52). Transfection of miR-19a mimics and miR-19a inhibitor did not change the RNA metabolism in VSMCs, suggesting that TIA1 may not be involved in the regulation of miR-19a. However, the present study only conducted in vivo experiments and the role of miR-19a in animal models with cardiovascular diseases will be explored in the future. 
In conclusion, the present study demonstrated that miR-19a promotes VSMC proliferation, migration and invasion via the MMP/ $\alpha$-SMA/SM22 $\alpha$ signaling pathway and the cyclinD1/CDC25A signaling pathway. Moreover, miR-19a promotes VSMC proliferation, migration and invasion via the MMP/ $\alpha$-SMA/SM22 $\alpha$ signaling pathway by inhibiting RHOB. This may provide understanding for myocardial infarction or stroke, or even atherosclerosis.

\section{Acknowledgements}

Not applicable.

\section{Funding}

No funding was received.

\section{Availability of data and materials}

The analyzed datasets generated during the study are available from the corresponding author on reasonable request.

\section{Authors' contributions}

GS and SW made substantial contributions to the conception and design of the study. SW, HS and GS were involved in data acquisition, analysis and interpretation. SW and HS drafted the article or critically revised it for important intellectual content. HS and GS agreed to be accountable for all aspects of the work in ensuring that questions related to the accuracy or integrity of the work are appropriately investigated and resolved. All authors read and approved the final manuscript.

\section{Ethics approval and consent to participate}

Not applicable.

\section{Patient consent for publication}

Not applicable.

\section{Competing interests}

The authors declare that they have no competing interests.

\section{References}

1. Beckman JA, Creager MA and Libby P: Diabetes and atherosclerosis: Epidemiology, pathophysiology, and management JAMA 287: 2570-2581, 2002.

2. Barsness GW, Peterson ED, Ohman EM, Nelson CL, DeLong ER, Reves JG, Smith PK, Anderson RD, Jones RH, Mark DB and Califf RM: Relationship between diabetes mellitus and long-term survival after coronary bypass and angioplasty. Circulation 96 2551-2556, 1997.

3. Natarajan MK, Strauss BH, Rokoss M, Buller CE, Mancini GB, Xie C, Sheth TN, Goodhart D, Cohen EA, Seidelin P, et al: Randomized trial of insulin versus usual care in reducing restenosis after coronary intervention in patients with diabetes. The STent restenosis and metabolism (STREAM) study. Cardiovasc Revasc Med 13: 95-100, 2012.

4. El Akoum S, Cloutier I and Tanguay JF: Vascular smooth muscle cell alterations triggered by mice adipocytes: Role of high-fat diet. J Atheroscler Thromb 19: 1128-1141, 2012.
5. Hattori Y, Hattori S, Sato N and Kasai K: High-glucose-induced nuclear factor kappaB activation in vascular smooth muscle cells. Cardiovasc Res 46: 188-197, 2000.

6. Wu WY, Yan H, Wang XB, Gui YZ, Gao F, Tang XL, Qin YL, $\mathrm{Su} \mathrm{M}$, Chen T and Wang YP: Sodium tanshinone IIA silate inhibits high glucose-induced vascular smooth muscle cell proliferation and migration through activation of AMP-activated protein kinase. PLoS One 9: e94957, 2014.

7. Virmani R, Kolodgie FD, Burke AP, Farb A and Schwartz SM: Lessons from sudden coronary death: A comprehensive morphological classification scheme for atherosclerotic lesions. Arterioscler Thromb Vasc Biol 20: 1262-1275, 2000

8. Bajaj A, Sethi A, Rathor P, Suppogu N and Sethi A: Acute complications of myocardial infarction in the current Era: Diagnosis and management. J Investig Med 63: 844-855, 2015.

9. Libby P, Ridker PM and Hansson GK: Progress and challenges in translating the biology of atherosclerosis. Nature 473: 317-325, 2011.

10. Bennett MR, Sinha S and Owens GK: Vascular smooth muscle cells in atherosclerosis. Circ Res 118: 692-702, 2016.

11. Kim J, Jang SW, Park E, Oh M, Park S and Ko J: The role of heat shock protein 90 in migration and proliferation of vascular smooth muscle cells in the development of atherosclerosis. J Mol Cell Cardiol 72: 157-167, 2014.

12. Pan HW, Li SC and Tsai KW: MicroRNA dysregulation in gastric cancer. Curr Pharm Des 19: 1273-1284, 2013.

13. Lim LP, Lau NC, Garrett-Engele P, Grimson A, Schelter JM, Castle J, Bartel DP, Linsley PS and Johnson JM: Microarray analysis shows that some microRNAs downregulate large numbers of target mRNAs. Nature 433: 769-773, 2005.

14. Lewis BP, Burge CB and Bartel DP: Conserved seed pairing, often flanked by adenosines, indicates that thousands of human genes are microRNA targets. Cell 120: 15-20, 2005.

15. Zhou Y, Li S, Li J, Wang D and Li Q: Effect of microRNA-135a on Cell Proliferation, migration, invasion, apoptosis and tumor angiogenesis through the IGF-1/PI3K/Akt signaling pathway in non-small cell lung cancer. Cell Physiol Biochem 42: 1431-1446, 2017.

16. Wu P, Agnelli L, Walker BA, Todoerti K, Lionetti M, Johnson DC, Kaiser M, Mirabella F, Wardell C, Gregory WM, et al: Improved risk stratification in myeloma using a microRNA-based classifier. Br J Haematol 162: 348-359, 2013.

17. Tian Z, Zhao JJ, Tai YT, Amin SB, Hu Y, Berger AJ, Richardson P, Chauhan D and Anderson KC: Investigational agent MLN9708/2238 targets tumor-suppressor miR33b in MM cells. Blood 120: 3958-3967, 2012.

18. Li T, Yang GM, Zhu Y, Wu Y, Chen XY, Lan D, Tian KL and Liu LM: Diabetes and hyperlipidemia induce dysfunction of VSMCs: Contribution of the metabolic inflammation/miRNA pathway. Am J Physiol Endocrinol Metab 308: E257-E269, 2015.

19. Mackenzie NC, Staines KA, Zhu D, Genever P and Macrae VE: miRNA-221 and miRNA-222 synergistically function to promote vascular calcification. Cell Biochem Funct 32: 209-216, 2014.

20. Chen Q, Yang F, Guo M, Wen G, Zhang C, Luong le A, Zhu J, Xiao Q and Zhang L: miRNA-34a reduces neointima formation through inhibiting smooth muscle cell proliferation and migration. J Mol Cell Cardiol 89: 75-86, 2015.

21. Hayashita Y, Osada H, Tatematsu Y, Yamada H, Yanagisawa K, Tomida S, Yatabe Y, Kawahara K, Sekido Y and Takahashi T: A polycistronic microRNA cluster, miR-17-92, is overexpressed in human lung cancers and enhances cell proliferation. Cancer Res 65: 9628-9632, 2005.

22. Zhao D, Chen Y, Chen S, Zheng C, Hu J and Luo S: MiR-19a regulates the cell growth and apoptosis of osteosarcoma stem cells by targeting PTEN. Tumour Biol 39: 1010428317705341, 2017.

23. Zhong B, Guo S, Zhang W, Zhang C, Wang Y and Zhang C: Bioinformatics prediction of miR-30a targets and its inhibition of cell proliferation of osteosarcoma by up-regulating the expression of PTEN. BMC Med Genomics 10: 64, 2017.

24. Roberts PJ, Mitin N, Keller PJ, Chenette EJ, Madigan JP, Currin RO, Cox AD, Wilson O, Kirschmeier P and Der CJ: Rho Family GTPase modification and dependence on CAAX motif-signaled posttranslational modification. J Biol Chem 283: 25150-25163, 2008.

25. Etienne-Manneville S and Hall A: Rho GTPases in cell biology. Nature 420: 629-635, 2002

26. MeyerN,Peyret-Lacombe A,CanguilhemB,Médale-GiamarchiC, Mamouni K, Cristini A, Monferran S, Lamant L, Filleron T, Pradines A, et al: RhoB promotes cancer initiation by protecting keratinocytes from UVB-induced apoptosis but limits tumor aggressiveness. J Invest Dermatol 134: 203-212, 2014. 
27. Calvayrac O, Pradines A, Raymond-Letron I, Rouquette I, Bousquet E, Lauwers-Cances V, Filleron T, Cadranel J, Beau-Faller M, Casanova A, et al: RhoB determines tumor aggressiveness in a murine EGFRL858R-induced adenocarcinoma model and is a potential prognostic biomarker for lepidic lung cancer. Clin Cancer Res 20: 6541-6550, 2014.

28. Huang $M$ and Prendergast GC: RhoB in cancer suppression. Histol Histopathol 21: 213-218, 2006.

29. Niu S, Ma X, Zhang Y, Liu YN, Chen X, Gong H, Yao Y, Liu K and Zhang X: MicroRNA-19a and microRNA-19b promote the malignancy of clear cell renal cell carcinoma through targeting the tumor suppressor RhoB. PLoS One 13: e0192790, 2018.

30. Chen Q, Guo W, Zhang Y, Wu Y and Xiang J: MiR-19a promotes cell proliferation and invasion by targeting RhoB in human glioma cells. Neurosci Lett 628: 161-166, 2016.

31. Chan KC, Wu CH, Huang CN, Lan KP, Chang WC and Wang CJ: Simvastatin inhibits glucose-stimulated vascular smooth muscle cell migration involving increased expression of RhoB and a block of Ras/Akt signal. Cardiovasc Ther 30: 75-84, 2012.

32. Chan KC, Lin MC, Huang CN, Chang WC and Wang CJ: Mulberry 1-deoxynojirimycin pleiotropically inhibits glucose-stimulated vascular smooth muscle cell migration by activation of AMPK/RhoB and down-regulation of FAK. J Agric Food Chem 61: 9867-9875, 2013.

33. Zhang N, Fu L, Bu Y, Yao Y and Wang Y: Downregulated expression of miR-223 promotes Toll-like receptor-activated inflammatory responses in macrophages by targeting RhoB. Mol Immunol 91: 42-48, 2017.

34. Livak KJ and Schmittgen TD: Analysis of relative gene expression data using real-time quantitative PCR and the 2(-Delta Delta C(T)) method. Methods 25: 402-408, 2001

35. Malumbres $\mathbf{M}$ and Barbacid M: Mammalian cyclin-dependent kinases. Trends Biochem Sci 30: 630-641, 2005.

36. Boutros R, Lobjois V and Ducommun B: CDC25 phosphatases in cancer cells: Key players? Good targets? Nat Rev Cancer 7: 495-507, 2007.

37. Ray D, Terao Y, Nimbalkar D, Hirai H, Osmundson EC, Zou X, Franks R, Christov K and Kiyokawa H: Hemizygous disruption of Cdc25A inhibits cellular transformation and mammary tumorigenesis in mice. Cancer Res 67: 6605-6611, 2007.

38. Blomberg I and Hoffmann I: Ectopic expression of Cdc25A accelerates the $G(1) / S$ transition and leads to premature activation of cyclin E- and cyclin A-dependent kinases. Mol Cell Biol 19: 6183-6194, 1999.

39. Timofeev O, Cizmecioglu O, Settele F, Kempf T and Hoffmann I: Cdc25 phosphatases are required for timely assembly of CDK1-cyclin B at the G2/M transition. J Biol Chem 285: 16978-16990, 2010.

40. Cai FG, Xiao JS and Ye QF: Effects of ischemic preconditioning on cyclinD1 expression during early ischemic reperfusion in rats. World J Gastroenterol 12: 2936-2940, 2006.
41. Gopalakrishnan N, Saravanakumar M, Madankumar P, Thiyagu $M$ and Devaraj $H$ : Colocalization of $\beta$-catenin with Notch intracellular domain in colon cancer: A possible role of Notch1 signaling in activation of CyclinD1-mediated cell proliferation. Mol Cell Biochem 396: 281-293, 2014.

42. Visse R and Nagase H: Matrix metalloproteinases and tissue inhibitors of metalloproteinases: Structure, function, and biochemistry. Circ Res 92: 827-839, 2003.

43. Chambers AF and Matrisian LM: Changing views of the role of matrix metalloproteinases in metastasis. J Natl Cancer Inst 89: 1260-1270, 1997.

44. Polette M, Nawrocki-Raby B, Gilles C, Clavel C and Birembaut P: Tumour invasion and matrix metalloproteinases. Crit Rev Oncol Hematol 49: 179-186, 2004.

45. Li WD, Hu N, Lei FR, Wei S, Rong JJ, Zhuang H and Li XQ: Autophagy inhibits endothelial progenitor cells migration via the regulation of MMP2, MMP9 and uPA under normoxia condition. Biochem Biophys Res Commun 466: 376-380, 2015.

46. Fatar M, Stroick M, Griebe M and Hennerici M: Matrix metalloproteinases in cerebrovascular diseases. Cerebrovasc Dis 20: 141-151, 2005.

47. Yuan SM: $\alpha$-Smooth muscle actin and ACTA2 gene expressions in vasculopathies. Braz J Cardiovasc Surg 30: 644-649, 2015

48. Zhang JC, Kim S, Helmke BP, Yu WW, Du KL, Lu MM, Strobeck M, Yu Q and Parmacek MS: Analysis of SM22alphadeficient mice reveals unanticipated insights into smooth muscle cell differentiation and function. Mol Cell Biol 21: 1336-1344, 2001.

49. Wang J, Zhou H, Han Y, Liu X, Wang M, Wang X, Yin G, Li X and Xiang M: SOCS3 methylation in synergy with Reg3A overexpression promotes cell growth in pancreatic cancer. J Mol Med (Berl) 92: 1257-1269, 2014.

50. Chen Y, Wang W, Chen Y, Tang Q, Zhu W, Li D and Liao L: MicroRNA-19a-3p promotes rheumatoid arthritis fibroblast-like synoviocytes via targeting SOCS3. J Cell Biochem 2019 (Epub ahead of print)

51. Li Y, Luo T, Wang L, Wu J and Guo S: MicroRNA-19a-3p enhances the proliferation and insulin secretion, while it inhibits the apoptosis of pancreatic $\beta$ cells via the inhibition of SOCS3. Int J Mol Med 38: 1515-1524, 2016.

52. Tian Q, Streuli M, Saito H, Schlossman SF and Anderson P: A polyadenylate binding protein localized to the granules of cytolytic lymphocytes induces DNA fragmentation in target cells. Cell 67: 629-639, 1991.

c) (i) $\odot$ This work is licensed under a Creative Commons

Attribution-NonCommercial-NoDerivatives 4.0 International (CC BY-NC-ND 4.0) License. 